\title{
Evaluation of Protective Effect of a Water-In-Oil Microemulsion Incorporating Quercetin Against UVB-Induced Damage in Hairless Mice Skin
}

\author{
Fabiana T. M. C. Vicentini ${ }^{1}$, Yris M. Fonseca ${ }^{1}$, Dimitrius L. Pitol ${ }^{2}$, Mamie M. Iyomasa ${ }^{2}$, M. Vitória L. B. Bentley ${ }^{1}$, Maria J. \\ V. Fonseca ${ }^{1 *}$ \\ ${ }^{1}$ Faculdade de Ciências Farmacêuticas de Ribeirão Preto - Universidade de São Paulo, São Paulo, Brazil \\ ${ }^{2}$ Faculdade de Odontologia de Ribeirão Preto - Universidade de São Paulo, São Paulo, Brazil
}

Received, January 4, 2010; Revised, June 15, 2010; Accepted, August 4, 2010; Published, August 5, 2010.

\begin{abstract}
Purpose. Histological aspects were considered in order to evaluate the in vivo photoprotective effect of a w/o microemulsion containing quercetin against UVB irradiation-induced dermal damages. The toxicity in cell culture and the potential skin irritation resulting from topical application of this formulation were investigated. Methods. Mouse dorsal surfaces were treated topically with $300 \mathrm{mg}$ of the unloaded and quercetin-loaded $(0.3 \%, \mathrm{w} / \mathrm{w})$ microemulsions before and after exposure to UVB $\left(2.87 \mathrm{~J} / \mathrm{cm}^{2}\right)$ irradiation. The untreated control groups irradiated and non-irradiated were also evaluated. UVB-induced histopathological changes as well as the photoprotective effect of this formulation were evaluated considering the parameters of infiltration of inflammatory cells, epidermis thickening (basale and spinosum layers) and collagen and elastic fiber contents. The cytotoxicity of the reported formulation was evaluated in L929 mice fibroblasts by MTT assay and the skin irritation was investigated after topical application of both unloaded and quercetin-loaded microemulsions once a day for 15 days. Results. The results demonstrated that the w/o microemulsion containing quercetin reduced the incidence of histological skin alterations, mainly the connective-tissue damage, induced by exposure to UVB irradiation. This suggests that protective effects of this formulation against UVinduced responses are not secondary to the interference of UV transmission (i.e., blocking the UVB radiation from being absorbed by the skin), as is usually implied with UVB absorbers and sunscreens, but is instead due to different biological effects of this flavonoid. Furthermore, by evaluating the cytotoxic effect on L929 cells and histological aspects such as infiltration of inflammatory cells and epidermis thickness of hairless mice, the present study also demonstrated the lack of toxicity of the proposed system. Conclusion. Based on these mice models, a detailed characterization of the w/o microemulsion incorporating quercetin effects as a photochemoprotective agent on human skin is presented.
\end{abstract}

\section{INTRODUCTION}

The UV components of sunlight are now recognized as major environmental factors deleterious to human health. Photodamage, the specific damage produced in skin tissue by single or repeated (cumulative) exposure to UV light (290-400 nm), is considered to be an initiating step of photocarcinogenesis. UV irradiation-induced injury to the skin can be subdivided into acute and chronic photodamage (1). Acute exposure to UV irradiation from the sun is harmful to skin, causing sunburn, immune suppression, DNA damage and connective tissue degradation. Accumulated damage, resulting from chronic sun exposure, causes skin cancer and premature skin aging (photoaging) $(2,3)$.
UV irradiation is known to alter cellular function via DNA damage and inflammatory responses. In addition, damage to the extracellular matrix integrity in skin tissues is an important event entailing skin wrinkle and blister formation, hallmarks of photoaging (4).

Skin connective tissue (dermis) provides structural support for the skin's vasculature, appendages and epidermis, which are vital to the function of the skin. Structural integrity and function of the dermis are primarily dependent on its extracellular matrix, which is primarily composed of type I collagen fibrils.

Corresponding Author: Faculdade de Ciências Farmacêuticas de Ribeirão Preto, Universidade de São Paulo, Av. do Café s/n, CEP 14040-903, Ribeirão Preto, São Paulo, Brazil. E-mail address: magika@,fcfrp.usp.br (M.J.V.Fonseca). 
Type I collagen is the most abundant structural protein in skin, and fragmented collagen fibrils are prominent, characteristic features of aged human skin in vivo. This fragmentation seriously impairs both the mechanical properties of skin and the functions of cells that reside within the dermis (5). Dermal damage induced by UV irradiation is principally manifested histologically as the disorganization of collagen fibrils and the accumulation of abnormal elastin-containing material. Biochemical evidence of connective-tissue alteration in photoaged skin includes reduced levels of types I and III collagen precursors and crosslinks, an increased ratio of type III to type I collagen and an increased level of elastin (6).

In principle, conscientious use of sunscreens/blocks or protective clothing should prevent UVB exposure of the skin. Unfortunately, practical considerations encompassing the use of inadequate amounts of sunscreen and the popularity of tanning appear to limit the success of approaches aimed at reducing skin sun exposure (7). Thus, considering that the use of sunscreen and sun block are not completely effective in preventing UVinduced skin cancer, new targeted chemopreventive approaches need to be identified.

Strategies to prevent early pathological events induced by UV light may be useful for providing efficient and adequate photoprotection. One approach to ameliorate adverse effects of UVB on the skin is the use of antioxidants scavenging and quenching reactive oxygen species (ROS) (4). The therapeutic application of antioxidants in photoprotection is based on the photooxidative stress hypothesis. If this hypothesis is correct, generation of ROS, depletion of antioxidants, damage of the type caused by ROS and activation of redox sensitive signal transduction pathways can be expected in irradiated skin. Manipulation of skin antioxidants would affect both these molecular changes and subsequent biological and clinical sequela (3).

Quercetin, one of the most common flavonoid in nature, is reported to have antioxidant properties associated with antithrombic, antihypertensive, anticarcinogenic and anti-inflammatory effects (8). The protective effects of quercetin have been attributed to the inhibition of key signaling enzymes (e.g. protein kinase $\mathrm{C}$, tyrosine kinase and phosphoinositide 3-kinase) involved in the regulation of cell proliferation, angiogenesis and apoptosis, as well as to antioxidant properties as scavengers of ROS (9).

In our previous study, the potential of a w/o microemulsion as a topical carrier system for delivery of the antioxidant quercetin was demonstrated (10). In the present study, histological aspects were considered in order to evaluate the in vivo photoprotective effect of this formulation against UVB irradiation-induced dermal damages.

\section{MATERIAL AND METHODS}

\section{Materials}

Quercetin dihydrate $99 \%\left(\mathrm{C}_{15} \mathrm{H}_{10} \mathrm{O}_{7} \cdot 2 \mathrm{H}_{2} \mathrm{O}, \mathrm{M}_{\mathrm{w}}=\right.$ 338.26) was purchased from Acros Organics (New Jersey, USA). Dulbecco's modified Eagle medium (DMEM), fetal bovine serum (FBS) and antibiotic solution containing $5 \mathrm{mg}$ of penicillin, $5 \mathrm{mg}$ of streptomycin and $10 \mathrm{mg}$ of neomycin per $\mathrm{ml}$ were purchased from Gibco (Grand Island, NY, USA). Propylene glycol and polyoxyethylene (80) sorbitan monolaurate (Tween $80^{\circledR}$ ) were from Synth (Diadema, SP, Brazil), sorbitan monolaurate (Span $80^{\circledR}$ ), Sirius red and glutaraldehyde $25 \%$ were obtained from Sigma Chemical Co. (St. Louis, MO, USA) and orceine was purchased from Merck (Darmstadt, Germany). All other chemicals were of reagent grade and were used without further purification.

\section{Microemulsion containing quercetin}

Microemulsion was prepared by adding the following components to the final stated percentages $(\mathrm{w} / \mathrm{w}): 15 \%$ of a mixture of propylene glycol and water (3:1) as water phase, $46.75 \%$ of a mixture of Span $80^{\circledR}$ and Tween $80^{\circledR}(3: 1)$ as the surfactant/co-surfactant system and $38.25 \%$ of canola oil as the external phase. Quercetin $(0.3 \%$, $\mathrm{w} / \mathrm{w})$ was incorporated into this system as previously described (10).

\section{Protective effect of a microemulsion containing quercetin against UVB irradiation- induced skin damages}

\section{Animals and experimental protocol}

In vivo experiments were performed on 3-monthold sex matched hairless mice obtained from the colony of the Faculty of Pharmaceutical Science of Ribeirao Preto; They were housed in a temperature- 
controlled room, with access to water and food ad libitum until use. All experiments were conducted in accordance with National Institutes of Health guidelines for the welfare of experimental animals and with the approval of the Ethics Committee of the Faculty of Pharmaceutical Science of Ribeirao Preto (University of Sao Paulo, Ribeirao Preto, SP, Brazil).

Randomly chosen animals were divided into groups of 3-5 and topically treated on the dorsal surface with $300 \mathrm{mg}$ of the unloaded (quercetin free microemulsion - ME) or quercetin-loaded $(0.3 \%$, $\mathrm{w} / \mathrm{w})(\mathrm{ME}+\mathrm{Q})$ microemulsions. The formulations were applied $1 \mathrm{~h}$ and $5 \mathrm{~min}$ before irradiation of the dorsal surface and also immediately after irradiation as previously described (11). The untreated control groups, irradiated and non-irradiated, were included in the experiments.

\section{Irradiation}

The UVB source of irradiation consisted of a Philips TL40W/12 RS lamp (Medical-Eindhoven, Holand) i.e. city, country?), mounted $20 \mathrm{~cm}$ above the table on which the mice were placed, and which emitted a continuous light spectrum between 270 and $400 \mathrm{~nm}$ with a peak emission at $313 \mathrm{~nm}$. UVB output $(80 \%$ of the total UV irradiation) was measured using a model IL-1700 Research Radiometer (International Light, USA; calibrated by IL service staff) with a radiometer sensor for UV (SED005) and UVB (SED240). The UVB irradiation rate was $0.27 \mathrm{~mW} / \mathrm{cm}^{2}$ and the dose used was $2.87 \mathrm{~J} / \mathrm{cm}^{2}$.

\section{Erythema formation}

The increase in skin erythema, after irradiation ( $3 \mathrm{~h})$ and before animal sacrifice $(6 \mathrm{~h})$, was measured using the Chroma Meter CR 200 (Minolta Instrument Systems, Milton Keynes, UK), and readings on the $\mathrm{a}^{*}$ scale, which measures the intensity of redness of skin were recorded. The increase in this redness was expressed as the difference between the basal a* (before irradiation) and irradiated skin values.

\section{Histopathological changes}

UVB-induced histopathological changes were evaluated considering the parameters of infiltration of inflammatory cells, epidermis thickening (basale and spinosum layers) and collagen and elastic fiber contents.
The animals were sacrificed with an overdose of carbon dioxide $6 \mathrm{~h}$ after the start of UVB exposure, and the skin treated area was dissected and fixed by immersion into $2.5 \%$ glutaraldehyde in cacodylate buffer solution at room temperature for $24 \mathrm{~h}$. Following dehydration and inclusion in paraffin wax, $5 \mu \mathrm{m}$ thick sections were cut and stained with hematoxylin and eosin (H\&E), Sirius red and orceine.

In the H\&E stained sections, a test-system composed of points and cycloid arcs was overlaid on the captured images, and thicknesses of the basale and spinosum layers of epidermis were measured by stereological analysis counting the points on the epithelium and the intersections with the interface of layers (12). Sirius red and orceine staining were used to determine the collagen and elastic fiber contents, respectively. Stained sections were examined with light microscopy, and the images were captured at $100 \mathrm{X}$ magnification. The collagen and elastic fiber contents were evaluated using the ImageJ Program (NIH-National Institute of Health, Bethesda, Maryland, USA) software.

\section{Microemulsion cytotoxicity and skin irritation}

\section{Determination of cytotoxicity}

Cell culture and treatment

L929 mice fibroblast from the Rio de Janeiro cell Bank, University of Rio de Janeiro, Rio de Janeiro, Brazil, were routinely grown in $150 \mathrm{~cm}^{2}$ tissue culture flasks in DMEM supplemented with 1\% $(\mathrm{v} / \mathrm{v})$ of an antibiotic solution containing $5 \mathrm{mg}$ of penicillin, $5 \mathrm{mg}$ of streptomycin and $10 \mathrm{mg}$ of neomycin per $\mathrm{ml}$, as well as with $7.5 \%(\mathrm{v} / \mathrm{v})$ heatinactivated FBS, at $37^{\circ} \mathrm{C}$ under $5 \% \mathrm{CO}_{2}$. Quercetin (raw material) was dissolved in dimethyl sulfoxide (DMSO, final concentration below $0.1 \%$ ) and diluted using phosphate buffer solution (PBS), and $\mathrm{ME}$ and $\mathrm{ME}+\mathrm{Q}$ were dissolved in PBS. The final quercetin concentrations ranged from $50-400$ $\mu \mathrm{g} / \mathrm{mL}$. Then, $20 \mu \mathrm{L}$ of each dilution was used in the MTT assay.

\section{MTT assay}

The sensitivity of cells to quercetin activity was determined by a standard spectrophotometric 3(4,5-dimethylthiazole-2-yl)-2,5-diphenyltetrazolium bromide (MTT) assay (13). Cells were seeded at a cell density of $10^{5}$ cells/well into 96 well plates and 
incubated for $24 \mathrm{~h}$ at $37^{\circ} \mathrm{C}$ in an atmosphere of $95 \%$ air and $5 \% \mathrm{CO}_{2}$. Then, $20 \mu \mathrm{L}$ of quercetin (raw material), $\mathrm{ME}$ and $\mathrm{ME}+\mathrm{Q}$, at different concentrations in PBS, were added to culture plates for $24 \mathrm{~h}$. After treatment, cells were rinsed twice with PBS, and the serum free culture medium without phenol red was replaced in all wells. Cells were then incubated for $4 \mathrm{~h}$ with the MTT solution (5 $\mathrm{mg} / \mathrm{mL}$ ). The yellow tetrazolium salt was metabolized by viable cells to purple crystals of formazan. The crystals were solubilized overnight in a mixture consisting of $20 \%$ sodium dodecyl sulfate (SDS) in $\mathrm{HCl}(0.01 \mathrm{M})$. The product was quantified spectrophotometrically by absorbance measurement at a $570 \mathrm{~nm}$ wavelength using a microplate reader $\left(\mu\right.$ Quant $^{\mathrm{TM}}$, BioTek Instruments Inc., Vermount, USA). The cellular viability was expressed as the percentage of viable cells compared to the control group.

\section{Determination of skin irritation}

ME and ME+Q (300 mg) were applied topically and non-occlusively on a limited area of the dorsal skin of hairless mice once a day for 15 days, and the animals were sacrificed on the sixteenth day with an overdose of carbon dioxide. The skins of untreated animals were used as controls. The histological analyses were conducted as described above, and skin irritation was evaluated according to the established endpoints of infiltration of inflammatory cells and epidermis thickening (basale and spinosum layers).

\section{Statistical analyses}

Data were statistically analyzed by one-way ANOVA, followed by Bonferroni's multiple comparisons $t$-test. The evaluations were made using the GraphPad Prism ${ }^{\circledR}$ (GraphPad Software,
San Diego, California, USA) and results considered significantly different when $p<0.05$ was obtained.

\section{RESULTS}

Protective effect of a microemulsion containing quercetin against UVB irradiation- induced skin damages

\section{Erythema formation}

A comparison of the UV-induced skin reddening of ME- and ME+Q- treated skin to untreated skin was performed. Neither unloaded nor quercetin-loaded microemulsion pretreatment conferred protection against $\mathrm{UV}$-induced skin reddening (Table 1).

\section{Histopathological changes}

Histological examination of hairless mice skin exposed to UVB irradiation revealed an exulcerated epidermis with bandlike inflammatory infiltrates in the dermal connective tissue and also, as demonstrated by arrows in Figure 1, the formation of sunburn cells (apoptotic keratinocytes). However, the topical treatment with both $\mathrm{ME}$ and $\mathrm{ME}+\mathrm{Q}$ decreased the severity of the UVB-induced histological effects, reducing the extent of formation of sunburn cells by about $66 \%$ (data not shown).

The preventive effects of the w/o microemulsion containing quercetin on the UVBinduced skin thickening were evaluated by directly measuring the thickness of the basale and spinosum layers of epidermis. The UVB induced epidermal hyperproliferation (skin fold thickness increased by $30 \%$ ) was significantly reduced by the treatment with both ME and ME+Q (Figure 2 and Table 2).

\begin{tabular}{lcc}
\hline \multicolumn{2}{l}{ Table 1. Effect of unloaded and quercetin-loaded microemulsions treatment on UVB-induced erythema } \\
formation in hairless mice skin 3 and 6 hours after the beginning of UV exposure. \\
\hline \multicolumn{3}{c}{ Skin reddening $\left(\Delta \mathbf{a}^{*}\right)$} \\
Treatment & $\mathbf{3 ~ h}$ & $\mathbf{6 ~} \mathbf{~ h}$ \\
\hline Control & $0.07 \pm 0.02$ & $0.13 \pm 0.00$ \\
Irradiated & $7.83 \pm 0.13$ & $7.68 \pm 0.12$ \\
$\mathrm{ME}$ & $7.78 \pm 0.05$ & $7.63 \pm 0.11$ \\
$\mathrm{ME}+\mathrm{Q}$ & $7.72 \pm 0.10$ & $7.69 \pm 0.11$ \\
\hline$\Delta \mathrm{a}^{*}$ corresponds to the difference between basal a* (skin color before irradiation) and irradiated skin values \\
Results are represented by means \pm S.D. $(\mathrm{n}=3)$.
\end{tabular}



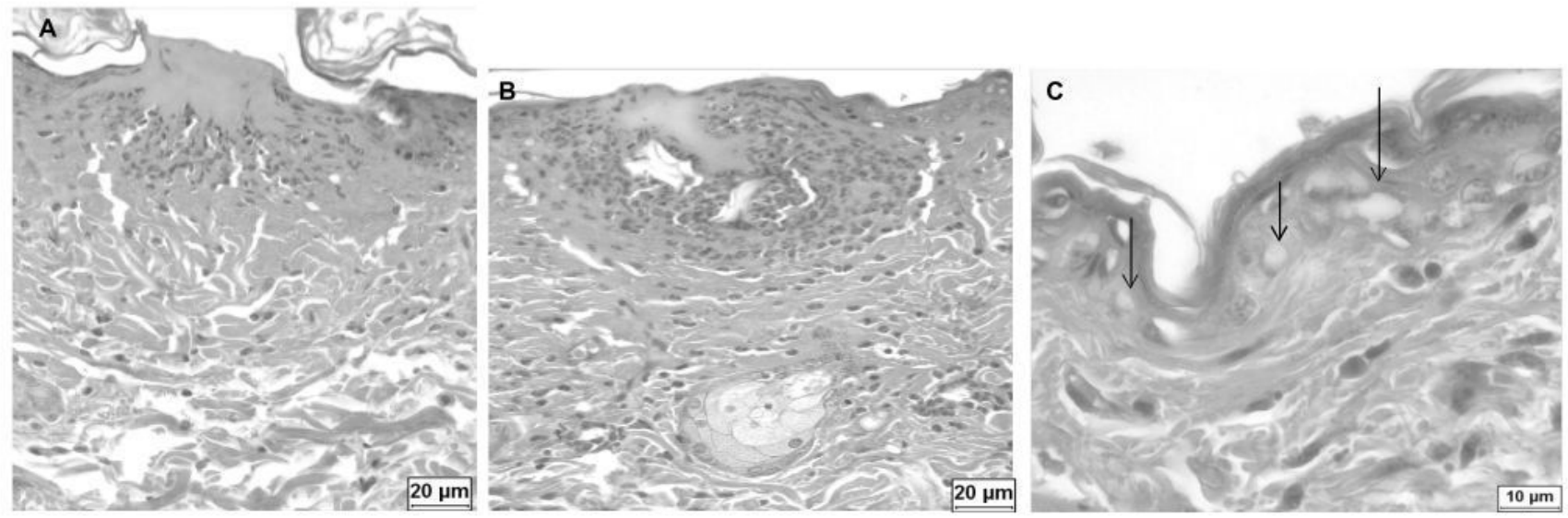

Figure 1. UVB-induced histopathological changes in hairless mice skin. Representative photomicrographs of samples derived from untreated-irradiated animals. Sections (A) and (B) were analyzed through a 40X objective and section (C) through a $100 \mathrm{X}$ objective and stained by hematoxylin and eosin (H\&E).
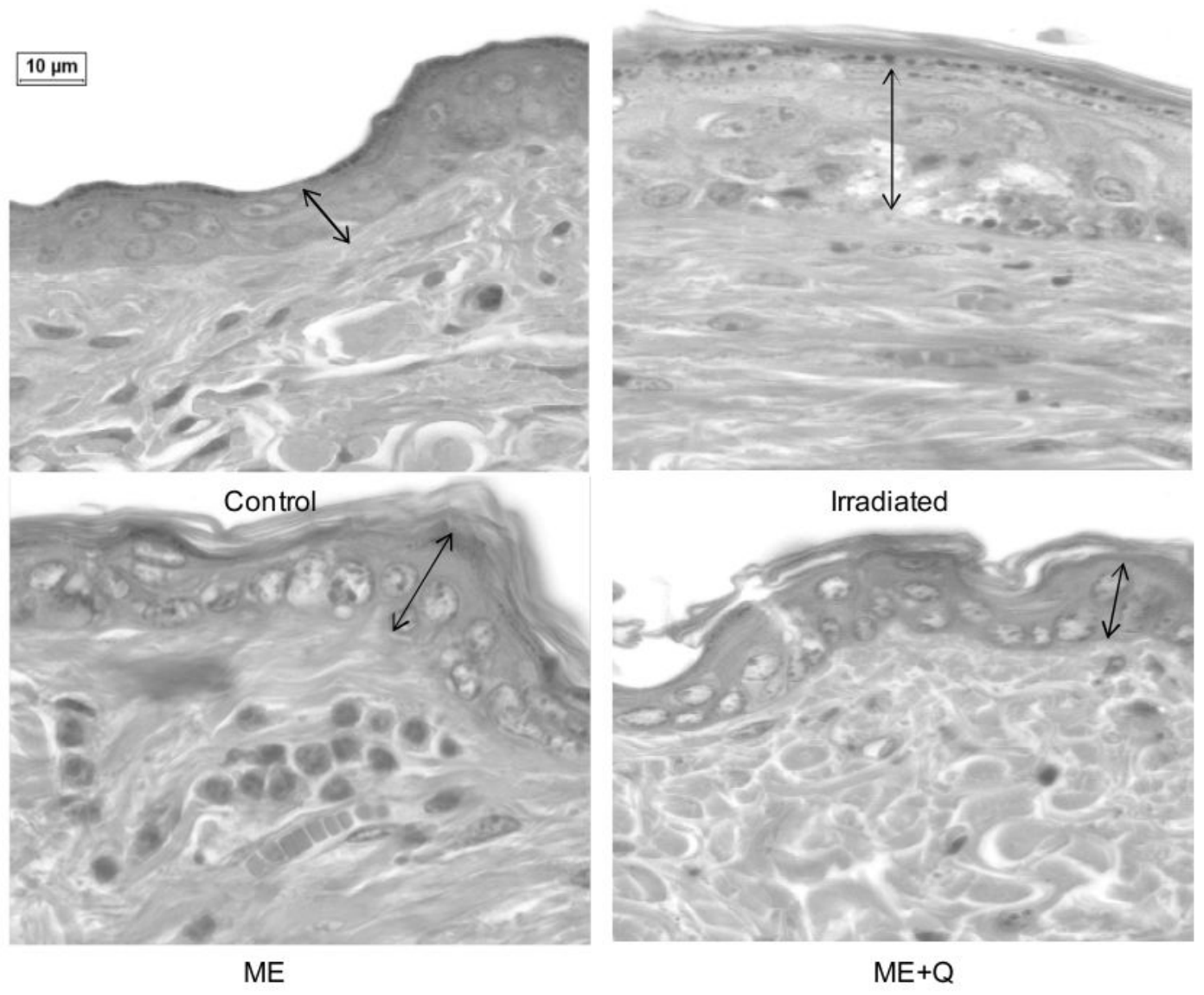

Figure 2. Effect of a w/o microemulsion on UVB-induced histopathological alterations. Representative photomicrographs of samples derived from untreated-unexposed skin (control), untreated-irradiated skin (irradiated), ME and ME+Q treated skins. Sections were visualized by conventional light microscopy through a 100X objective and stained by hematoxylin and eosin (H\&E). 
Sirius red stained sections showed damage to the collagen in the upper epidermis of untreated irradiated skin. As demonstrated by Figure 3A, these changes were less pronounced in the $\mathrm{ME}+\mathrm{Q}$ treated group. Finally, as demonstrated by Figure $3 \mathrm{~B}$, in non-irradiated skin, fine elastic fibers perpendicular and parallel to the body axis were observed in the lower dermis. On the other hand, in untreated irradiated skin, a significant accumulation of elastic fibers in the lower epidermis was found, with a detected increase of about $54 \%$ in the numerical density of the elastic fibers when compared with the control group. In the group of animals pre-treated with both $\mathrm{ME}$ and $\mathrm{ME}+\mathrm{Q}$, an increase in the elastic fiber levels of approximately $29 \%$ was detected when compared with the control group (untreated-unexposed group), reducing the extent of UVB-induced elastic fiber level increase by $25 \%$ when compared with the untreatedirradiated group (data not shown).

\section{Microemulsion cytotoxicity and skin irritation}

\section{Cytotoxicity}

It is important to mention that because of the interference of redox sensitive molecules which may reduce the MTT irrespective of any cellular mechanism and therefore give false positive results,

\begin{tabular}{ll}
\hline $\begin{array}{l}\text { Table 2. Epidermis thickness of hairless mice after UVB exposure and treatment with unloaded and } \\
\text { quercetin-loaded microemulsions. } \\
\text { Treatment }\end{array}$ & Epidermis thickness $\mathbf{s}^{\mathbf{a}}(\boldsymbol{\mu \mathbf { m }})$ \\
\hline Control & $8.55 \pm 0.87$ \\
Irradiated & $11.05 \pm 1.63^{*}$ \\
$\mathrm{ME}$ & $6.65 \pm 1.12$ \\
$\mathrm{ME}+\mathrm{Q}$ & $6.23 \pm 1.15$ \\
\hline${ }^{\mathrm{a}}$ Corresponds to the sum of basale and spinosum layers of epidermis. Results are represented by means \pm S.D. \\
( $\mathrm{n}=5)$. Statistical analysis was performed by one-way ANOVA followed by Bonferroni's test of multiple \\
comparisons. *Significant statistical difference compared to control (untreated-unexposed group) $(p<0.05)$. \\
\hline
\end{tabular}

A

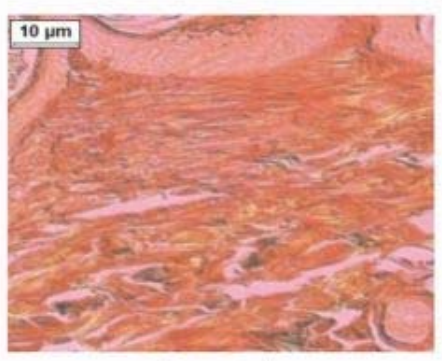

Control

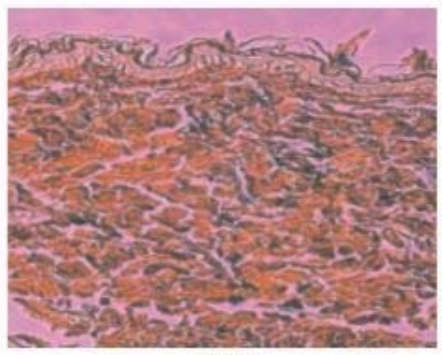

ME

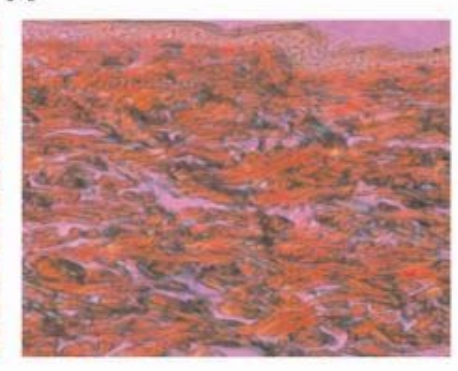

Irradiated

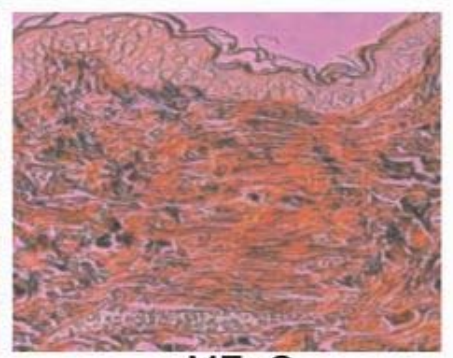

$\mathrm{ME}+\mathrm{Q}$

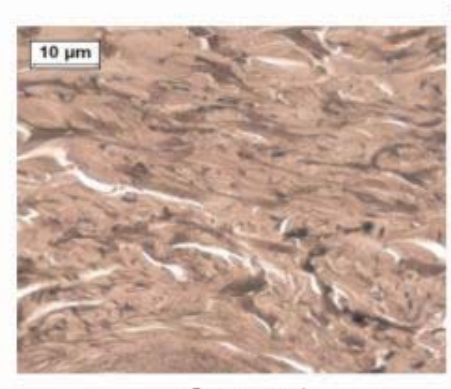

Control

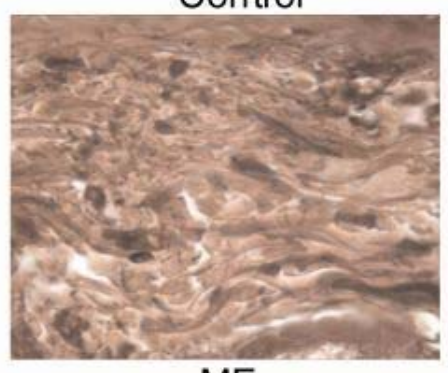

ME
B

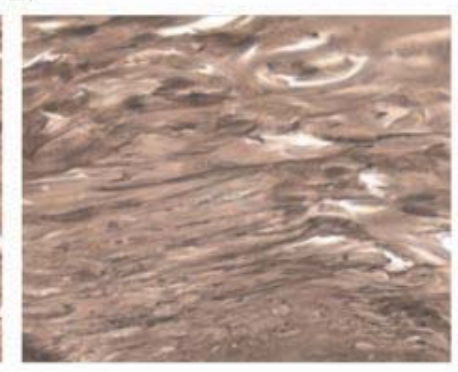

Irradiated

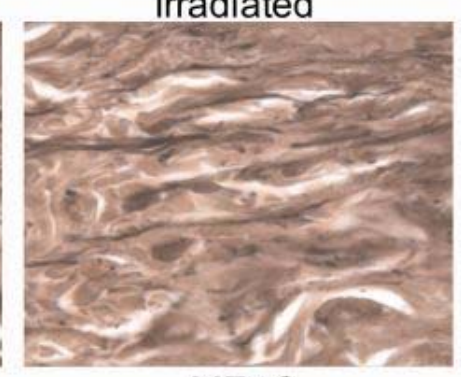

$\mathrm{ME}+\mathrm{Q}$

Figure 3. Effect of a w/o microemulsion on collagen and elastic fibers content in the skin of hairless mice exposed to UVB irradiation. Representative photomicrographs of (A) collagen and (B) elastic fibers in the skin. Sections were visualized by conventional light microscopy through a 100X objective and stained by sirius red for collagen and by orceine for elastic fibers analysis. 
some cautions during the cytotoxicity experiments were taken, as suggested by Bruggisser, $\mathrm{R}$. et al. (14). Firstly, a prescreening in cell-free systems was performed to examine the potential reductive activity of quercetin before the performance of any cell culture experiment. The results demonstrated that only the highest concentration of quercetin (400 $\mu \mathrm{g} / \mathrm{mL}$ ) employed in the present study showed some interference. Subsequently, washing procedures were implemented to properly remove the potentially interfering agent before the addition of MTT.

The effects on cell proliferation of quercetin as well as the unloaded and quercetin-loaded microemulsions were evaluated. The incubation with quercetin (raw material) for $24 \mathrm{~h}$ induced a concentration-dependent inhibition of cell proliferation as determined by MTT assay (Table 3). The inhibition was $18.28,23.34$ and $32.50 \%$ at 100,200 and $400 \mu \mathrm{g} / \mathrm{mL}$ of quercetin, respectively. The evaluation of unloaded and quercetin-loaded microemulsion cytotoxicity demonstrated that, until the concentration corresponded to $200 \mu \mathrm{g} / \mathrm{mL}$ of quercetin, the formulations protected against quercetin cytotoxicity since no inhibition of cell proliferation was observed. Nevertheless, for the highest concentration studied, the reduction in cell viability was about $65 \%$ for $\mathrm{ME}+\mathrm{Q}$, due to the sum of the cytotoxic effects of both quercetin and unloaded ME.

\section{Skin irritation}

Previous work by our group demonstrated that the daily application of $\mathrm{ME}+\mathrm{Q}$ for up to 2 days did not cause skin irritation (10). However, a deeper investigation should be conducted in order to evaluate the effect of this formulation when applied over a greater period of time. Therefore, in the present work, the histopathological changes in the skin of hairless mice were evaluated after administration (for 15 consecutive days) of the proposed formulation with and without quercetin. The formulations were applied topically and nonocclusively on a limited area of the dorsal skin of hairless mice once a day for 15 days, and the animals were sacrificed on the sixteenth day and the skin analyzed.

No histopathological alterations in the skin of animals treated with $\mathrm{ME}$ and $\mathrm{ME}+\mathrm{Q}$ were seen by light microscopy, as compared to the untreated animals (Figure 4A). Furthermore, no statistical difference was observed in the thicknesses of the basale (Figure 4B) and spinosum (Figure 4C) layers of epidermis in topically ME-treated and ME+Qtreated groups when compared to untreated animals.

\begin{tabular}{|c|c|c|c|}
\hline \multirow{2}{*}{$\begin{array}{l}\text { Quercetin concentration } \\
(\mu \mathrm{g} / \mathrm{mL})\end{array}$} & \multicolumn{3}{|c|}{ Cellular viability (\% of control) } \\
\hline & $\begin{array}{l}\text { Quercetin (raw } \\
\text { material) }\end{array}$ & ME & $\mathbf{M E}+\mathbf{Q}$ \\
\hline 50 & $103.26 \pm 6.77$ & $105.64 \pm 7.11$ & $98.98 \pm 8.02$ \\
\hline 100 & $81.72 \pm 9.95$ & $116.03 \pm 8.39$ & $114.10 \pm 9.10$ \\
\hline 200 & $76.66 \pm 14.37$ & $91.99 \pm 17.33$ & $118.33 \pm 6.39$ \\
\hline 400 & $67.50 \pm 5.67$ & $63.12 \pm 25.38$ & $35.19 \pm 10.95$ \\
\hline
\end{tabular}

\section{DISCUSSION}

Chronic exposure of skin to solar UV radiation markedly alters the composition and architecture of the dermal extracellular matrix, resulting in both clinical and histologic changes in human skin. Both UVB (290-320 nm) and UVA (320-400 nm) portions of the terrestrial solar UV spectrum are believed to contribute to the processes that initiate these responses. UVB is almost entirely absorbed by cellular components in the epidermis, suggesting that dermal remodeling initiated by this waveband involves mediators that diffuse from the epidermis into the dermis, where they stimulate fibroblast production of elastin and glycosaminoglycans (15).

UV irradiation causes increased synthesis and release of proinflammatory mediators from a variety of skin cells, leading to infiltration and activation of neutrophils and other phagocytic cells into the skin. 

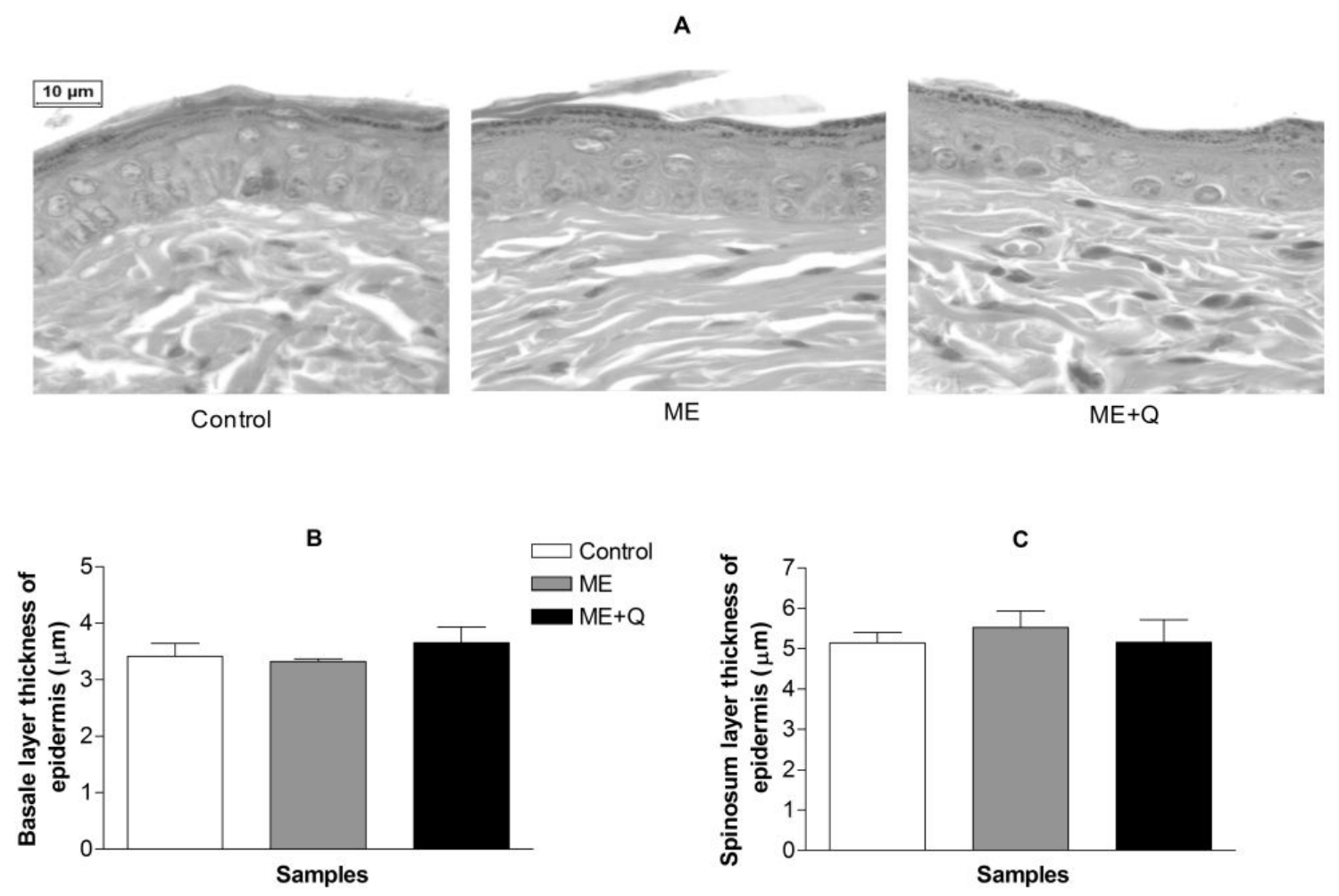

Figure 4. Effect of a w/o microemulsion in the skin of hairless mice. (A) Representative photomicrographs of skin sections of untreated animals and treated with $\mathrm{ME}$ and $\mathrm{ME}+\mathrm{Q}$. Sections were visualized by conventional light microscopy through a 100X objective and stained by hematoxylin and eosin (H\&E). Panels (B) and (C) show the thickness of the basale and spinosum layers of epidermis, respectively, of untreated animals and treated with ME and ME+Q. Results are represented by means \pm S.E.M. ( $n=5$ animals per group). No statistical significant difference was detected. Statistical analysis was performed by one-way ANOVA followed by Bonferroni's test of multiple comparisons $(p<0.05)$.

Thus, inflammatory mechanisms may accentuate the effect of UV radiation to amplify direct damaging effects on molecules and cells that cause photoaging (4).

In the present work, the acute exposure of hairless mice to a UVB dose of $2.87 \mathrm{~J} / \mathrm{cm}^{2}$ induced an immediate inflammatory response with erythema and leukocyte infiltration. Statistically significant increases were also observed in the epidermis thickness, the collagen and fiber levels and the formation of sunburn cells, a marker of the severity of solar damage (1). These increases in connective tissues may increase skin fold thickness and lead to the formation of skin wrinkles by UV.

It has been suggested that the modulation of redox-sensitive transcription factors, such as nuclear factor (NF)- $\kappa \mathrm{B}$, by ROS is a central and early event in the induction of inflammatory reactions (16). NF- $\mathrm{kB}$ is an oxidative stresssensitive factor that activates multiple target genes involved in the expression of several proinflammatory mediators (17). Quercetin, a member of the flavonoid family, is known to modulate NF- $\mathrm{\kappa B}$ activation triggered by various inductors in different cell types (18-26).

The use of antioxidant compounds as photoprotective agents for preventing premature skin ageing and skin disease seems appropriate. In this context, it is important to mention that vitamin $\mathrm{E}$, which is recognized as the most important lipidsoluble, chain-breaking antioxidant in the body, is probably the most widely investigated photoprotective substance besides sunscreens, being indicated as playing a key role in the prevention of skin oxidative damage (27). Therefore, the topical use of the lipid-soluble free-radical scavenger 
quercetin may be relevant for a preventive and/or therapeutic approach to photoprotection.

Previous work by our group reported the effectiveness of topical formulations containing quercetin against damage induced by UVB radiation exposure (11). However, incorporation into a w/o microemulsion optimized the effects of the flavonoid, since a dosage approximately 6 -fold smaller produced the same in vivo results obtained with a non-ionic emulsion containing quercetin (10).

Among the in vivo effects, topical treatment with $\mathrm{ME}+\mathrm{Q}$ inhibited the activity of matrix metalloproteinases (MMPs) in skin exposed to UVB irradiation, probably via MMP inhibition (10). MMPs are a family of proteolytic enzymes that specifically degrade collagens, elastin and other proteins in connective tissue and bone (6).

MMPs are frequently over expressed by various extracellular stimuli including growth factors, cytokines, tumor promoters and UV, and this increase in MMP-related activities may be involved in the pathogenesis of diseases such as cancer and inflammation, as well as in physiologic processes. It has been reported that up-regulation of some MMPs is responsible for the enhanced degradation of dermal collagen during chronological and UVinduced skin aging (28-30). Therefore, the regulation of MMP activity might be a potential strategy for prevention and/or treatment of UVinduced skin damage (31).

The present study demonstrated that $\mathrm{ME}+\mathrm{Q}$ was able to reduce the incidence of UV irradiationinduced histological skin alterations, mainly the connective-tissue damage. More recently, changes in collagen metabolism have been brought into focus as a major factor leading to photoaging. Specifically, it has been found that the accumulation of elastic material is accompanied by concomitant degeneration of the surrounding collagenous meshwork, and evidence implicating MMPs as mediators of collagen damage in photoaging has been presented (32). Thus, the capability of $\mathrm{ME}+\mathrm{Q}$ to inhibit the UVB-induced activity of MMPs resulted in decreased incidence of extracellular matrix damage upon topical application of this formulation in hairless mice.

Furthermore, considering that ROS play an important role in the upregulation and activation of extracellular matrix-degrading MMPs and are able to attack and destroy per se several extracellular matrix proteins, the antioxidant properties of quercetin may also be responsible for preventing this degradation and, consequently, the deleterious effects of photoaging agents.

The topical treatment of hairless mice with the $\mathrm{ME}+\mathrm{Q}$ maintained reduced glutathione (GSH) levels close to the non-irradiated control, which demonstrates that this formulation significantly prevented UVB irradiation-induced GSH depletion (10). GSH is an endogenous tripeptide that plays an important role in protection against photooxidative damage. It can act as a direct free radical scavenger by hydrogen atom donation, and the resulting much less reactive thienyl radicals decay bimolecularly or via an oxygen-dependent mechanism, forming glutathione disulfide GSSG (33).

Quercetin may protect against UV-induced GSH depletion either by free radical scavenging activity or by decreasing free radical production through iron chelation since, in addition to its antiradical activity, quercetin possess structural features that enable it to chelate metal ions, namely the ortho dihydroxy (catechol) phenolic structure. Besides this, the protective effects of this flavonoid can be also due to cellularly-mediated effects such as increased enzymatic and non-enzymatic cellular antioxidants, perhaps by stimulating the cytoplasmic machinery involved in the enzymatic resynthesis of GSH. Therefore, the effects of quercetin seem to be due to effects at several levels that include radical scavenging, iron chelation and modulation of cell antioxidant responses (34).

Thus, by evaluating the effects of $\mathrm{ME}+\mathrm{Q}$ on UV-induced erythema formation and histopathological changes, it is possible to suggest that the protective effects of this formulation on UV-induced responses reported above are not secondary to interference of UV transmission (i.e., blocking the UVB radiation from being absorbed by the skin), as is usually done with UVB absorbers and sunscreens, but is instead due to different biological effects of this flavonoid.

Furthermore, the present study also demonstrated that, although the ME is composed of large amounts of surfactants and oil, the $24 \mathrm{~h}$ incubation of L929 cells with the quercetin-loaded microemulsion has no cytotoxic effect until the final concentration reaches $200 \mu \mathrm{g} / \mathrm{mL}$. Additionally, the daily application of both $\mathrm{ME}$ and $\mathrm{ME}+\mathrm{Q}$ for up to 15 days did not cause skin irritation, as demonstrated by the evaluation of established 
endpoints of skin irritation. The irritability of emulsifiers has been demonstrated in a wide variety of experimental models, and it may cause MEs to have an irritative effect on living cells. The interactions between stratum corneum lipids and MEs may cause dehydration and barrier function compromise. In experimental models, these effects cannot always be neatly separated, since barrier compromise will increase irritant penetration and hence increase the irritative effect (35).

As epidemiological studies indicate that the use of sunscreen and sun block are not completely effective in preventing UV-induced skin cancer, new targeted chemopreventive approaches need to be identified (36). Instead of only blocking the UVB radiation from being absorbed by the skin, as is usually done with UVB absorbers and sunscreens, skin could be also protected by preventing the formation of the photooxidants that result in radical damage and cutaneous pathology (37). In this context, the topical application of $\mathrm{ME}+\mathrm{Q}$ was able to reduce the incidence of histological skin alterations in UV-irradiated hairless mice. Therefore, the present results taken together with the previous data on skin retention and in vivo activity (10) suggest that further investigation should be conducted in order to evaluate the effects of $\mathrm{ME}+\mathrm{Q}$ as a photochemoprotective agent on human skin.

\section{ACKNOWLEDGMENTS}

This work was supported by "Coordenação de Aperfeiçoamento de Pessoal de Nível Superior" (CAPES, Brazil) and "Fundação de Amparo à Pesquisa do Estado de São Paulo" (FAPESP, Brazil). F.T.M.C.Vicentini was the recipient of a CAPES fellowship. The authors are grateful to Dr. Pedro Alves da Rocha Filho for permitting the use of the Chroma Meter CR 200 and for Nilce O. Wolga and Gilberto André e Silva for technical assistance.

Novelty of the Work: This manuscript evaluates the histological aspects involved in UVB-induced acute skin damages and the protective effect of a w/o microemulsion containing quercetin against these dermal damages. The present results allowed a better understanding about the photoprotective effect of this formulation, suggesting that further studies should be conducted in order to evaluate its effects on human skin.

Keywords: Quercetin, skin, microemulsion, ultraviolet irradiation, histological investigation, dermal damage, toxicity, photoprotective effect

\section{REFERENCES}

1. Farkas B, Magyarlaki M, Csete B, Nemeth J, Rabloczky G, Bernath S, Literati Nagy P, Sumegi B. Reduction of acute photodamage in skin by topical application of a novel PARP inhibitor. Biochem Pharmacol, 63: 921-932, 2002.

2. Xu Y, Shao Y, Voorhees JJ, Fisher GJ. Oxidative inhibition of receptor-type protein-tyrosine phosphatase kappa by ultraviolet irradiation activates epidermal growth factor receptor in human keratinocytes. J Biol Chem, 281: 27389-27397, 2006.

3. Fuchs J. Potentials and limitations of the natural antioxidants RRR-alpha-tocopherol, L-ascorbic acid and beta-carotene in cutaneous photoprotection. Free Radic Biol Med, 25: 848-873, 1998.

4. Bae JY, Lim SS, Kim SJ, Choi JS, Park J, Ju SM, Han SJ, Kang IJ, Kang YH. Bog blueberry anthocyanins alleviate photoaging in ultraviolet-B irradiation-induced human dermal fibroblasts. Mol Nutr Food Res, 53: 726-738, 2009.

5. Fisher GJ, Quan T, Purohit T, Shao Y, Cho MK, He $\mathrm{T}$, Varani J, Kang S, Voorhees JJ. Collagen fragmentation promotes oxidative stress and elevates matrix metalloproteinase-1 in fibroblasts in aged human skin. Am J Pathol, 174: 101-114, 2009.

6. Fisher GJ, Wang ZQ, Datta SC, Varani J, Kang S, Voorhees JJ. Pathophysiology of premature skin aging induced by ultraviolet light. N Engl J Med, 337: 1419-1428, 1997.

7. $\mathrm{Xu} \mathrm{Y,} \mathrm{Voorhees} \mathrm{JJ,} \mathrm{Fisher} \mathrm{GJ.} \mathrm{Epidermal} \mathrm{growth}$ factor receptor is a critical mediator of ultraviolet $B$ irradiation-induced signal transduction in immortalized human keratinocyte $\mathrm{HaCaT}$ cells. Am J Pathol, 169: 823-830, 2006.

8. Ruiz PA, Braune A, Holzlwimmer G, QuintanillaFend L, Haller D. Quercetin inhibits TNF-induced NF-kappaB transcription factor recruitment to proinflammatory gene promoters in murine intestinal epithelial cells. J Nutr, 137: 1208-1215, 2007.

9. Morrow DM, Fitzsimmons PE, Chopra M, McGlynn H. Dietary supplementation with the anti-tumour promoter quercetin: its effects on matrix metalloproteinase gene regulation. Mutat Res, 480481: 269-276, 2001.

10. Vicentini FT, Simi TR, Del Ciampo JO, Wolga NO, Pitol DL, Iyomasa MM, Bentley MV, Fonseca MJ. Quercetin in w/o microemulsion: in vitro and in vivo 
skin penetration and efficacy against UVB-induced skin damages evaluated in vivo. Eur $\mathrm{J}$ Pharm Biopharm, 69: 948-957, 2008.

11. Casagrande R, Georgetti SR, Verri WA, Jr., Dorta DJ, dos Santos AC, Fonseca MJ. Protective effect of topical formulations containing quercetin against UVB-induced oxidative stress in hairless mice. J Photochem Photobiol B, 84: 21-27, 2006.

12. Mandarim-de-Lacerda CA. Stereological tools in biomedical research. An Acad Bras Cienc, 75: 469486, 2003.

13. Mosmann T. Rapid colorimetric assay for cellular growth and survival: application to proliferation and cytotoxicity assays. J Immunol Methods, 65: 55-63, 1983.

14. Bruggisser R, von Daeniken K, Jundt G, Schaffner $\mathrm{W}$, Tullberg-Reinert $\mathrm{H}$. Interference of plant extracts, phytoestrogens and antioxidants with the MTT tetrazolium assay. Planta Med, 68:445-448, 2002.

15. Wang $\mathrm{H}$, Kochevar IE. Involvement of UVBinduced reactive oxygen species in TGF-beta biosynthesis and activation in keratinocytes. Free Radic Biol Med, 38: 890-897, 2005.

16. Fuchs J, Zollner TM, Kaufmann R, Podda M. Redox-modulated pathways in inflammatory skin diseases. Free Radic Biol Med, 30: 337-353, 2001.

17. Carini M, Aldini G, Piccone M, Facino RM. Fluorescent probes as markers of oxidative stress in keratinocyte cell lines following UVB exposure. Farmaco, 55: 526-534, 2000.

18. Garcia-Roman R, Salazar-Gonzalez D, Rosas S, Arellanes-Robledo J, Beltran-Ramirez O, FattelFazenda S, Villa-Trevino S. The differential NFkappaB modulation by S-adenosyl-L-methionine, Nacetylcysteine and quercetin on the promotion stage of chemical hepatocarcinogenesis. Free Radic Res, 42: 331-343, 2008.

19. Hamalainen M, Nieminen R, Vuorela P, Heinonen M, Moilanen E. Anti-inflammatory effects of flavonoids: genistein, kaempferol, quercetin, and daidzein inhibit STAT-1 and NF-kappaB activations, whereas flavone, isorhamnetin, naringenin, and pelargonidin inhibit only NFkappaB activation along with their inhibitory effect on iNOS expression and NO production in activated macrophages. Mediators Inflamm, 2007: 45673, 2007.

20. Nair MP, Mahajan S, Reynolds JL, Aalinkeel R, Nair H, Schwartz SA, Kandaswami C. The flavonoid quercetin inhibits proinflammatory cytokine (tumor necrosis factor alpha) gene expression in normal peripheral blood mononuclear cells via modulation of the NF-kappa beta system. Clin Vaccine Immunol, 13: 319-328, 2006.
21. Dias AS, Porawski M, Alonso M, Marroni N, Collado PS, Gonzalez-Gallego J. Quercetin decreases oxidative stress, NF-kappaB activation, and iNOS overexpression in liver of streptozotocininduced diabetic rats. J Nutr, 135: 2299-2304, 2005.

22. Martinez-Florez S, Gutierrez-Fernandez B, SanchezCampos S, Gonzalez-Gallego J, Tunon MJ. Quercetin attenuates nuclear factor-kappaB activation and nitric oxide production in interleukin1beta-activated rat hepatocytes. J Nutr, 135: 13591365, 2005.

23. Shih CM, Lin H, Liang YC, Lee WS, Bi WF, Juan $\mathrm{SH}$. Concentration-dependent differential effects of quercetin on rat aortic smooth muscle cells. Eur $\mathbf{J}$ Pharmacol, 496: 41-48, 2004.

24. Cho SY, Park SJ, Kwon MJ, Jeong TS, Bok SH, Choi WY, Jeong WI, Ryu SY, Do SH, Lee CS, Song JC, Jeong KS. Quercetin suppresses proinflammatory cytokines production through MAP kinases andNF-kappaB pathway in lipopolysaccharide-stimulated macrophage. Mol Cell Biochem, 243: 153-160, 2003.

25. Rangan GK, Wang Y, Tay YC, Harris DC. Inhibition of NFkappaB activation with antioxidants is correlated with reduced cytokine transcription in PTC. Am J Physiol, 277: F779-789, 1999.

26. Sato M, Miyazaki T, Kambe F, Maeda K, Seo H. Quercetin, a bioflavonoid, inhibits the induction of interleukin 8 and monocyte chemoattractant protein1 expression by tumor necrosis factor-alpha in cultured human synovial cells. J Rheumatol, 24: 1680-1684, 1997.

27. Packer L, Valacchi G. Antioxidants and the response of skin to oxidative stress: vitamin $\mathrm{E}$ as a key indicator. Skin Pharmacol Appl Skin Physiol 15:282-290,2002.

28. Fisher GJ, Datta SC, Talwar HS, Wang ZQ, Varani J, Kang S, Voorhees JJ. Molecular basis of suninduced premature skin ageing and retinoid antagonism. Nature, 379: 335-339, 1996.

29. Rittie L, Fisher GJ. UV-light-induced signal cascades and skin aging. Ageing Research Reviews, 1: 705-720, 2002.

30. Brenneisen P, Wlaschek M, Schwamborn E, Schneider LA, Ma WJ, Sies H, ScharffetterKochanek K. Activation of protein kinase CK2 is an early step in the ultraviolet B-mediated increase in interstitial collagenase (matrix metalloproteinase-1; MMP-1) and stromelysin-1 (MMP-3) protein levels in human dermal fibroblasts. Biochemical Journal, 365: 31-40, 2002.

31. Moon HI, Lee J, Zee OP, Chung JH. The effect of flavonol glycoside on the expressions of matrix metalloproteinase-1 in ultraviolet-irradiated cultured human skin fibroblasts. J Ethnopharmacol, 101: 176179, 2005. 
32. Fujimori H, Hisama M, Shibayama H, Iwaki M. Protecting effect of phytoncide solution, on normal human dermal fibroblasts against reactive oxygen species. J Oleo Sci, 58: 429-436, 2009.

33. Sionkowska A. The influence of glutathione on the photochemical stability of collagen. Polymer Degradation and Stability, 73: 107-112, 2001.

34. Ramos AA, Lima CF, Pereira ML, FernandesFerreira M, Pereira-Wilson C. Antigenotoxic effects of quercetin, rutin and ursolic acid on HepG2 cells: Evaluation by the comet assay. Toxicology Letters, 177: 66-73, 2008.
35. Lehmann L, Keipert S, Gloor M. Effects of microemulsions on the stratum corneum and hydrocortisone penetration. Eur J Pharm Biopharm, 52: 129-136, 2001.

36. Cooper S, Ranger-Moore J, Bowden TG. Differential inhibition of UVB-induced AP-1 and NF-kappaB transactivation by components of the jun bZIP domain. Mol Carcinog (check abbreviation?), 43: 108-116, 2005.

37. Maalouf S, El-Sabban M, Darwiche N, GaliMuhtasib H. Protective effect of vitamin $\mathrm{E}$ on ultraviolet B light-induced damage in keratinocytes. Mol Carcinog check abbreviation?), 34: 121-130, 2002. 